\title{
Görsel Medyanın ve Subliminal Mesajların Çocuk Sağlı̆̆ı Üzerine Etkileri
}

\author{
Bahar Nur KANBUR*
}

\section{$\ddot{O} \mathbf{z}$}

Görsel medya, çocukların yaşamlarında büyük etkiye sahiptir. Çocukların davranışlarını, tutumlarını ve dünya görüşlerini şekillendirmesi sebebiyle sosyalleştirici etkisi en fazla olan araçlardan birisidir. Çocukların yaşamlarını zenginleştirmesi, sağlıksız davranışları değiştirmesi, eğitimi ve bilgiyi yaygınlaştırması, milli ve manevi değerlerin çocuğa kazandırılması, hoşgörüye teşvik etmesi, toplumsal farkları azaltmasını sağlayabilmesi gibi işlevleri bulunmaktadır. Ancak diğer bir açıdan bakıldığında görsel medya çocuğun hayal gücünü sınırlandırır, öğrenme güçlüğüne ve okul başarısında düşmeye neden olur. Şiddet içeren davranışlara teşvik etme, ahlaki değerlerin bozulmasına öncülük etme, sosyal duygusal duyarlılıkları azaltma, anksiyete, depresyon ve intihar davranışları üzerinde kolaylaştırıcı etki yapma, yerel kültürleri baskılama ve yabancılaşmaya katkı sağlama gibi olumsuz etkileri vardır. Televizyon, sinema, internet gibi görsel medya araçlarının içerdiği subliminal mesajlar çocuk üzerinde direkt bir etkiye sahip değildir, ancak dolaylı yoldan bilinçaltını etkileyerek çocukların davranışları üzerinde değişiklik yaratır. Çocukların görsel medya ile geçirdikleri sürenin uzunluğu göz önüne alındığında, çocuklar üzerinde olumsuz kalıcı etkileri olmaktadır. Çocuklar bu konu karşısında savunmasız durumda oldukları için çocuk ve görsel medya ilişkisi üzerinde dikkatle durulması gereken önemli bir konudur. Bu derlemenin amacı, görsel medya araçlarının içerdiği subliminal mesajların çocuk sağllğı üzerindeki olumsuz etkilerini literatür bilgileri ışı̆̆ında sunmaktır.

Anahtar Kelimeler: Çocuk, görsel medya, çocuk sağlı̆̆ı, subliminal mesajlar.

\section{Derleme Makale (Review Article)}

Geliş / Received: 02.10.2019 \& Kabul / Accepted: 22.10.2019

* Öğr. Gör., İstanbul Gelişim Üniversitesi, Sağlık Bilimleri Yüksekokulu, Hemşirelik Bölümü, İstanbul, Türkiye, E-posta: bnkanbur@gelisim.edu.tr ORCID ID https://orcid.org/oooo0002-9150-476X 


\title{
The Effects of Visual Media and Subliminal Messages on Child Health
}

\begin{abstract}
Visual media shapes children's behaviors, attitudes and their perception of the world, and it is one of the most socializing tools. Thus, visual media has a significant effect on children's lives. It has positive aspects such as enriching the lives of children, changing unhealthy behaviors, disseminating education and knowledge, bringing national and spiritual values to children, encouraging tolerance, and reducing social differences. With a different point of view, visual media limits the child's imagination, school success and causes learning difficulties. Furthermore, it has also negative aspects including encouraging violent behavior, leading to the deterioration of moral values, reducing social-emotional sensitivities, facilitating effects on anxiety, depression and suicidal behaviors, suppressing local cultures and contributing to alienation. Although visual media including television, cinema, and the internet does not have a direct effect on children, they could affect children's subconscious indirectly with subliminal messages. As a result, it may cause changes in their behaviors._Given the amount of time children spend with visual media, it has long-lasting negative effects on children. Since children are vulnerable to this issue, the relationship between children and visual media is an important issue that needs to be considered carefully. The aim of this review is to present the negative effects of subliminal messages in visual media on child health according to the current literature.
\end{abstract}

Keywords: Child, visual media, child health, subliminal messages.

\section{Giriş}

Bebekler iletişime hazır bir şekilde dünyaya gelir ve çevreleriyle sürekli iletişim ve etkileşim içine girerler. Gördükleri her şeyi taklit ederek öğrenmeye başlarlar'. Kü̈çük yaşlarda öğrendikleriyle oluşturduğu bu zihinsel yapı çocuğun ileride kişiliğini oluşturacaktır². Çocuk için eğitim önce ailede başlar ve anne babalarından öğrendikleri ile hayata ilk adımlarını atarlar. Daha sonra bir program dâhilinde eğitim ve öğretimin yapıldığı okul hayatı başlarken, çocuğun okul dışı hayatı, arkadaş çevresi ve en önemlisi de kitle iletişim araçları çocuğu eğitmekte ve yönlendirmektedir³.

Çocuğun ilk beş-altı yllı geleceği şekillendirmede en önemli yıllardır . Çocuk kiminle, neyle uzun süre vakit geçirirse onun alışkanlıklarını kazanır. Televizyon, çizgi film, telefon gibi kitle iletişim araçları renkli ve hareketli uyaranları ile kimi zaman anne ve 
babalardan daha fazla belirleyici etkiye sahip olabilmektedir ${ }^{1}$. Subliminal mesajlar, bilinçaltına seslendiği için etkisi diğer mesajlardan daha hızlı ve geniştir. Bilinçaltı ikna yöntemleri ile çizgi filmlerde şiddet, ölüm, cinsellik, gerçek üstü olaylar ve millî duyguları yıpratan olumsuz mesajlar gizlenmektedir4.

\section{Bilinçaltı (Subliminal) Mesajlar}

Bilinç, kökeni Latince con (birlikte) ve scire (bilmek) kelimelerinden gelmektedir5. Bilinç, kişinin doğrudan tanıdığı ve farkında olduğu bir zihnin parçasıdır. Yaşamın ilk döneminde, belki de anne karnında oluşmaya başlar6 ${ }^{6}$. Bilinçaltı ise çevremizdeki görüntü, ses, mesaj gibi uyarımların farkında olmadan veya bilinçli olmadan insan zihnine yerleşmesidir7. Subliminal mesaj ise, bir objenin içine gömülü olan mesajdır. İnsan algısı limitlerinin altında kaldığı için fark edilemez ve doğrudan bilinçaltını etkileyen mesajlardır ${ }^{8}$. Organlarımızla algıladığımız uyarıların \%95’i bilinçaltı düzeyinde işlem gördüğü için aldığımız kararların \%95’ini hiç farkına varmadan almaktayız. Bu durum en mantıklı ve akılcı görülen kararlarımızın bile köklerinin derinlerdeki duygu birikimimizin belirleyiciliğinden geçtiğini göstermektedir` ${ }^{9}$

Bilinçaltı iknanın en bilindik çalışması James Vicary tarafından 1950 yılında yapılmıştır. New Jersey Fort Lee Sinema Salonunda bir filmin gösteriminde her beş saniyede bir ekrana mesajları gizlice yansıtan bir araçla Patlamış Mısır Ye ve Kola İç mesajı gönderilmiştir. Patlamış mısır (\%58) ve kola (\%18) satışlarında artış sağlanmıştır ${ }^{10}$. Diğer bir örnek ise; Camel markalı sigaranın simgesi olan tek hörgüçlü devedir. Dikkatle bakıldığında bu devenin ön bacağındaki erkek figürün çıplak bir erkek olduğu görülmektedir. Bu reklam ile cinsellik tüketicilere gizli bir mesajla hissettirilmeye çalışılmakta ve Camel marka sigaranın erkek sigarası olduğu açıkça vurgulanmaktadir ${ }^{11}$.

\section{Görsel Medya}

Medya, kitle iletişiminde kaynak ile alıcı arasındaki kanallara ile yazılı, görsel, görselişitsel ve dokunsal bazı kitle iletişim araçlarına verilen ortak isimdir. ${ }^{12,13}$. Ulusal ya da uluslararası düzeyde kişilerin ve toplumun hayatını etkileyen role sahiptir ${ }^{14}$. İnsanların beklentileri doğrultusunda haberin, eğlencenin kitleler arası dağıtımını sağlar. 
Görsel medya araçları televizyon, internet ve sinema olmak üzere üç şekilde karşımıza çıkmaktadır. Günümüzde televizyon kitle iletişim araçları içerisinde en önemli yeri tutmaktadır. Modern toplumlarda hızlı ve güvenilir habere ulaşmada en etkin medya

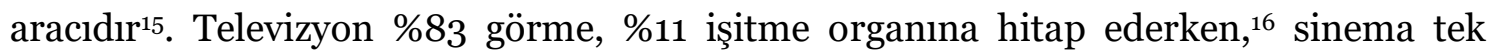
yönlü bir dışa vurum ve iletişim aracıdır. Bilgisayarın ise kitlelere arası iletişim aracı olarak kullanılması internetin kullanılmasıyla birlikte başlamıştır ${ }^{17}$.

\section{Televizyon ve Çocuk}

Aile ve Sosyal Politikalar Bakanlığının yaptığı araştırmaya göre Türkiye'de televizyon izlenme oranı \%91,9'dur. Araştırmalar çocukların televizyon izleme sürelerinin yetişkinlerden çok farklı olmadığını ortaya koymaktadır ${ }^{18}$. Çocuklar ve yetişkinlerin televizyon izleme nedenleri birbirinden farklılık göstermektedir. Çocuklar çok uzun saatler televizyona bağlı kalmaktadır. Bir çocuk ortalama günde en az 1-2 saat televizyon izlemektedir ${ }^{19}$. Çok sayıda hız değişimi, ses ve görüntünün uyumu, renklerin çekiciliği, ses efektleri ve müziğin dikkat çekici kullanımı çocuk için televizyonu cazip hale getirmektedir ${ }^{20,21}$.

Gerçekle hayal dünyasını ayırt edemeyecek ve gelişimsel özelliğini tamamlamamış olan okul öncesi dönemdeki çocuklar için televizyon olumsuz etkiye sahiptir. Özellikle o-3 yaş arasında uzun süre televizyon karşısında vakit geçiren çocuklarda konuşmaya başlamada ve jest-mimiklerin gelişmesinde yetersizlik ve gecikmeler görülmektedir ${ }^{22}$. Çocuklar uzun süre televizyon izlediklerinde, yüz yüze iletişim kurmakta zorlanan, etrafına ilgisiz, seslendiğinde tepki vermeyen, göz teması kuramayan, cümle kuramayan ve düzgün konuşamayan, sosyalleşme sorunları yaşayan çocuklar olmaktadır ${ }^{21}$. Şiddet gösterme ve agresif davranışlarda bulunma, öğrenme güçlügüu, okul başarısında azalma, depresyon, anksiyete uyku problemleri, gece korkuları, yeme bozuklukları, obezite ve cinsel davranış bozuklukları en önemli sorunların başında gelmektedir ${ }^{23}$. Vakit ve motivasyon eksikliğinden dolayı oyunlar ve aktiviteler ile kazanacakları motor beceriler yetersiz kalmakta ve ince motor becerilerin gelişimi ve anne babanın eğitimi için gerekli zaman azalmaktadır²4. Altınkılıç ve Özkan'ın 2014 yılında 1-6 yaş grubu çocuklarda yaptıkları çalışmada sağlık sorunu yaşama oranının günde bir saat televizyon izleyen çocuklarda \%36,2 saatten fazla televizyon izleyen çocuklarda \%69,3 olduğu bildirilmiştir. Bu çocukların göz ve uyku sağlığı ile ilgili daha fazla sorun yaşadıkları görülmektedir ${ }^{25}$. Çocuk televizyon karşısında uzun süre 
hareketsiz kaldığı için fiziksel haraketlilik ile enerji atımı yetersiz kalmaktadır 24 . Bu da çocuklarda obezite oranını artırmaktadır.

Televizyon, şiddet örnekleri sunan ve şiddeti bir model olarak gösteren programları sıklıkla göstermektedir ${ }^{26}$. Televizyonda suç işleme, işkence yapma gibi sahneleri sürekli izleyen çocuklarda şiddet karşısında duyarsızlaşma ve şiddeti normalleştirmesine neden olmaktadır ${ }^{27}$. Bir araştırmaya göre; "Kurtlar Vadisi” dizisinin tüm bölümlerini babasından dayak yiyen çocukların \%56'sı izlerken, babasından hiç dayak yemeyen çocukların sadece \%25’inin izlediği bildirilmiştir. Televizyon maruziyetine bağlı olarak çocuklarda ve gençlerde şiddet eğiliminde ve suça yönelmede önemli bir artış söz konusudur ${ }^{28}$. Ayrıca görsel medya, intihar düşüncesi olan çocuklarda intihar davranışını gerçekleştirme eğilimini arttırmaktadır ${ }^{29}$. Ergenler ise romantizm ile ilgili davranış senaryolarını, cinsel davranış normlarını televizyondan ve sosyal medyadan öğrenmektedirler. Daha küçük yaş grubundaki cinsellik konusunda bilgi ve deneyimi olmayan çocuklar da, çıplaklık içeren cinsel sahnelerden rahatsızlık duymaktadırlar. Cinsellik içeren sahneleri yanlış yorumlamakta ve şiddet olarak kavramsallaştırmaktadır ${ }^{30}$. Amerikan Pediatri Akademisi tarafından anne ve babalara iki yaşından küçük çocuklara televizyon izlettirilmemesi tavsiye edilmiştir. Televizyonun iki yaşından küçük çocuklar üzerinde olumlu hiçbir etki yaratmadığı hatta potansiyel olumsuz etki yarattığı vurgulanmaktadır ${ }^{1}$.

Televizyonun tüm bu olumsuz etkilerinin yanı sıra az da olsa olumlu etkileri de bulunmaktadır. Okul öncesi çocuklarda televizyonla eğitimin, erken okuma-yazmayı desteklediği ve belirli bir müfredatın öğretilmesini teşvik ettiği kanıtlanmıştır ${ }^{32}$. Bazı araştırmacılar televizyonun-çocukların akademik başarılarını olumlu etkilediğini bildirmişlerdir. Çocukların kendi yaşlarına uygun programları takip etmeleri zihinsel becerilerinin gelişmesine katkı sağlamakta ve zihinsel gelişimlerini olumlu etkilemektedir. Milli ve manevi değerlerin çocuğa kazandırılmasında önemli rolü bulunmaktadır33. Çocuklar birçok kelimeyi, sık kullanmadıkları eşyaların çalışması ile ilgili uygulamaları, ev hayvanlarının nasıl beslenmesi gerektiği gibi bilgileri televizyondan öğrenebilmektedirler ${ }^{34}$. Zihinsel sıralama ve düzenlemeleri daha kolay yapabilmekte, hayal kurup zihinsel imajlarını geliştirebilmektedir. Çünkü televizyon, yoğun bir uyarı vererek zihinsel bir değişim sağlayarak zekâyı şekillendirebilmektedir35. Okul öncesi dönemde diğer bir olumlu etkisi de dil gelişimine sağladığı faydadır. 1998 
yılında Singer tarafından yapılan çalışmada eğitici programların okul öncesi çocukluk döneminde bilişsel, sosyal yönden katkı sağladığı ve dil gelişimine olumlu etkisi olduğu bildirilmiştir ${ }^{3}$. Çocuklar görsel medya araçlarında gördüğü, duyduğu şeyleri kendi alanına geçirmekte ve bunların bir kısmı doğrudan yaşam biçimlerini etkilemektedir ${ }^{24}$. Saygı, sevgi, arkadaşlık, paylaşma gibi konularda önemli ölçüde katkı sağlamaktadır3¹.

\section{Çizgi Film ve Çocuk}

Halk arasında yaygın olarak kullanılan kavramı "çizgi film” olarak bilinirken Türk Dil Kurumu'nun kabul ettiği terim canlandırmadır. Türkçede ise hayat vermek anlamına gelmektedir ${ }^{6}$. Çocuklar televizyonda en çok çizgi film izlemektedirler ${ }^{37}$. Çizgi filmlerdeki renkli ve eğlenceli görüntüler, fantastik öğeler çocukların ilgisini çeker ve çok beğenirler ${ }^{38}$. Örneğin süper güçleri olan karakterler, konuşabilen hayvan karakterleri çocuklar için çok cazip olabilir. Bandura'nın Sosyal Öğrenme Teorisi’ne göre çocuklar etrafında gördüklerini taklit ederek öğrenirler. Medyaya karşı savunmasız alıcı konumunda olan çocuklar, çizgi filmlerde gördükleri karakterleri rol model alarak benzer davranışlar gösterebilirler ${ }^{39}$. Pek çok çocuk kendisini "Örümcek Adam", "Pokemon" ile özleştirebilir ve onlar gibi uçacağını zannederek yüksek yerlerden atlamaya çalışabilir ${ }^{20}$. Aksaçlıoğlu ve Yılmaz (2007)'ın yaptıkları çalışmada kızların \%80’inin erkeklerin ise \%91’inin çizgi film kahramanlarını örnek aldıkları bulunmuştur ${ }^{40}$. Özakar ve Koçak 2012 yılında yaptıkları çalışmada 3-6 yaş arasındaki çocuklara oyun oynarken çizgi film izletmişlerdir. Çocukların \%55,6'sının oyunu bırakıp çizgi film seyrettiği sadece \%16,7'sinin oyuna devam ettiği ve \%26,9'unun hem oyun oynayıp hem çizgi film seyrettiği bulunmuştur ${ }^{41}$.

Şiddet sahneleri çizgi filmler yoluyla çocuklara kontrolsüz bir şekilde aktarılmaktadır. Temel ve ark.'nın 2014 yılında çocuk kanallarındaki yayınlanan çizgi filmlerdeki şiddeti belirlemek amacıyla yaptıkları çalışmada çizgi filmlerin \%47,8'inde fiziksel, \%42,2'sinde ruhsal, \%35,6'sında sözel şiddet unsurları tespit edilirken, \%68,9'unda fiziksel, sözel, ruhsal şiddet unsurlarından en az biri bulunmuştur ${ }^{42}$. Çalışmalar çocukların şiddet içerikli çizgi film sahnelerini izlemekten hoşlandıkları ve erkek çocukların şiddet içeren çizgi filmleri daha çok tercih ettiğini göstermektedir ${ }^{41,43}$. Çocuklar karakterlerin birbirini dövmesinden, karakterlerin bıçaklanması, kanaması, patlaması gibi durumları izletmekten hoşlanmaktadırlar ${ }^{42}$. Çizgi film karakterlerinin şiddet eylemi sonrası ödüllendirilmesi, çocuğun bu karakteri daha fazla örnek almasına 
ve şiddetin daha kolay kabul edilebilir olmasına neden olmaktadır44. Çizgi filmlerde birçok subliminal mesaj bulunmaktadır. Örneğin kişi kendine benzeyen küçük bir grupla neşeli bir ömür sürebilir. Bunun için toplumdan soyutlanmalı ve toplum kurallarının geçerli olmadığı yeni bir dünya kurulmalıdır ${ }^{36}$.

\section{Reklam ve Çocuk}

Yeni bir tutum geliştirmek, var olan tutumu değiştirmek veya var olan tutumun şiddetini arttırma amaciyla oluşturulan reklamlar da çocuklar üzerinde etkili olmaktadır45. Çocukları etkilemek ve yönlendirmek daha kolay olduğundan reklam açısından çocuklar hedef grup olarak seçilmişlerdir ${ }^{46}$. Asena (2009)'ya göre 4-12 yaş arasındaki çocuklar sevdikleri şeylerle kolay bağ kurduklarından dolayı çocuklar için önem arz eden tüketici müşterilerdir. Çocuklar her yaşta reklamdan etkilenmelerine rağmen sekiz yaşına gelinceye kadar reklamın satış amaçlı yönünü anlamakta zorluk çekmektedirler ${ }^{47}$. Ateşoğlu ve Türkkahraman (2009)'a göre reklamlar çocukların ürünler, markalar hakkında bilgi alarak sosyalleşmelerine katkıda bulunurken, beslenme ve sağlık açısından gereksiz tüketime teşvik etmekte ve ahlaki davranışlar konusunda olumsuz etkilere neden olmaktadır48.

Televizyonda çoğunlukla çocukların harçlıkları ile alabileceği ürünlerin (şekerleme, sakız, bisküvi, dondurma, içecek ve fastfood'lar) reklamları yapılmaktadır ${ }^{46}$. Verilere göre, çocuklar yılda ortalama 20.000 ile 40.000 arasında reklam izlemektedir ${ }^{49}$. Kurt ve Altun (2004)'un ilköğretim 2. sınıf öğrencilerinde yaptıkları çalışmada öğrencilerin tümünün reklamlarda gördükleri yiyecekleri almayı tercih ettikleri ve reklamların öğrencilerin yiyecek tercihlerinde \%100 etkili olduğu bulunmuştur5o. Bu nedenle gün geçtikçe çocuklardaki aşırı kilo artışı ve obezite sorunu artmaktadır. Bunun yanı sıra televizyon karşısında hareketsiz şekilde kalan çocukların yetişkinlik dönemlerinde pek çok sorunla karşılaşma olasılığı fazladır. Bunların başında, bazı kanser türleri, şeker ve kalp hastalıkları gibi kronik hastalıklar gelmektedir51.

\section{Bilgisayar-İnternet ve Çocuk}

Çocuklar erken çocukluk döneminin sonlarına doğru bilgisayar gibi medya araçlarına yönelmektedirler52. Televizyonda şiddet içeren sahnelerin izlenmesi bile tehlikeli iken, internet oyunlarında çocuklar olayın içindedirler. Çocuk ve ergenlerin şiddet içerikli oyun oynama sıklı̆̆ı tahminlerin üstündedir. Ülkemizde 3975 ergen ile yapılan bir 
çalışmada, \%35,5’inin düzenli olarak şiddet içeren oyun oynadığı belirlenmiştir. Olson ve ark. (2007) yaptıkları bir çalışmada 12-14 yaş arası çocukların \%1,4’ünün daha önce hiç bilgisayar oyunu oynamadığı, \%48’inin en az bir şiddet içeren oyun oynadığı belirtilmiştir. Şiddet içeren oyun oynayan gençlerin oynamayanlar göre 2,5 kat daha cezalandırıcı davrandığı bildirilmiştir53.

Zamanın büyük bir bölümünü bilgisayarda oyun oynayarak geçiren çocuklar geleneksel oyun pratiğinden mahrum kalmakta ve toplumla temas etmekten yoksun kalmaktadır. Üzüntü ve sevincini karşısındakiyle paylaşamama, direkt konuşamama gibi iletişim sorunları yaşarken ${ }^{54}$, çocukların düşünme kapasitelerini sınırlandırmakta ve düşünce yetisi sığlaşan çocuklar gerek sözlü gerek yazılı olarak kendilerini yeterince ifade edememektedirler55.

\section{Sonuç ve Öneriler}

Son yıllarda yapılan çalışmalar özellikle televizyon, internet gibi görsel medya araçlarının kullanımının çocuklarda önemli derecede arttığını göstermektedir. $\mathrm{Bu}$ araçların içerisine gömülü olan subliminal mesajlar görülmektedir ki çocuklar için birçok olumsuz etkiye neden olmaktadır. Çocuklarda televizyon izlemeyi yasaklamak çözüm değildir. Öncelikle ebeveynler televizyon izlemeyi sınırlandırmayı kendilerine prensip edinmelidirler. Özellikle anneler çocuklarıyla daha çok zaman geçirmektedir ve bu yüzden televizyon izleme konusunda çocuğa çok iyi bir model olmalıdırlar. Çocukların aileleri ile geleneksel oyun oynamaları, çocuklarıyla daha fazla vakit geçirmeleri, televizyon programlarında yer alan bilgileri ve mesajları nasıl değerlendirmesi gerektiğini çocuklarına öğretmelidirler. Çocuklar vakitlerinin büyük bir bölümünü ebeveynlerinden sonra gelen ilk idolü öğretmenler ile okulda geçirmektedirler. Öğretmenlerin kitle iletişim araçlarını çocuklara akılcı ve etkili bir biçimde kullanmaları için yardımcı olmaları gerekir. Öğretim programlarına konulan medya okur-yazarlığı derslerine daha fazla önem verilmeli ve öğrenciler bilgilendirilmelidir. Televizyonda yayınlanan reklamlar çocuğu tamamen tüketime teşvik etmemeli, reklamların yazılmasında ve canlandırılmasında pedagoglar ve sağlık uzmanlarına daha fazla yer verilmelidir. Bir çizgi filmde ya da reklamda subliminal mesaj varlığını tespit etmek amacıyla özel analiz cihazları gerekmektedir. Çocukların hızlı bir büyüme gelişme süreci içinde olması, bilişsel düzeyleri, benlik kavramı baş etme yöntemleri ve sosyal davranışları yetişkinlere göre daha az gelişmiş olması 
sebebiyle pediatri hemşiresinin bu konuda daha özenli ve dikkatli olması gerekmektedir.

\section{KAYNAKLAR}

1. Pembecioğlu N, Gelecek Kurguları ve Medya Algıları. In: Yavuzer H, Şirin MR, eds. I. Türkiye Çocuk ve Medya Kongresi Bildiriler Kitabı.1. baskı. İstanbul: Çocuk Vakfı Yayınları; 2013.

2. Akyüz E, Çocuğun Bilgi Edinme ve Zararlı Yayınlara Karşı Korunma Hakkı. In: Yavuzer H, Şirin MR. I. Türkiye Çocuk ve Medya Kongresi Bildiriler Kitabı.1.baskı İstanbul: Çocuk Vakfı Yayınları; 2013.

3. Temizyürek F, Acar Ü. Çizgi filmlerdeki subliminal mesajların çocuklar üzerindeki etkisi. Cumhuriyet International Journal of Education. 2014;3(3):2529.

4. Yağlı A, Erdoğan F. Wakfu çizgi filminindeki subliminal mesajların okul öncesi çocukların tutum ve davranışlarına olumsuz etkileri. Social Sciences Studies Journal. 2018;4(23):4647-4658.

5. Gennaro RJ. Consciousness and concepts. Journal of Consciousness Studies. 2007;10:1-19.

6. Güler H. Algıların Ötesi: Bilinçaltı Reklamcılık, Bilinçaltı Reklamcılığın Tüketici Davranışları Üzerindeki Etkileri. [Yayımlanmamış yüksek lisans tezi]. Kocaeli, Türkiye: Kocaeli Üniversitesi Sosyal Bilimler Enstitüsü; 2008.

7. Küçükbezirci Y. Bilinçaltı mesaj gönderme teknikleri ve bilinçaltı mesajların topluma etkileri. International Periodical for the Languages, Literature and History of Turkish or Turkic. 2013;8(9):1879-1894.

8. Vokey JR. Subliminal messages. Psychological Sketches. 11th ed. Lethbridge, Alberta: Psyence Ink; 201: Chapter 21.

9. Baysal S, Akalın N. Pazarlamanın bilinçaltı. MediaCat Aylık Pazarlama Dergisi. 2011;202:60-68.

10. Darıcı S. Subliminal İşgal. İstanbul: Destek Yayınevi; 2012. 
11. Kurdar Y. Mysticism in subliminal advertising. Journal Academic Marketing Mysticism Online (JAMMO). 2012;4(15):222-239.

12. Dökmen Ü. İletişim Çatışmaları ve Empati. İstanbul: Sistem Yayınları; 2001.

13. Gani V. Medya ve eğitim. Yeni Türkiye Dergisi. 1996;12:1363-1367.

14. Sherman E, Chomsky N. Medya Halka Nasıl Evet Dedirtir? İstanbul: Minerva Yayınları; 1999.

15. Oğuz GY. Televizyon: kaçınılmaz öğreticimiz... Televizyonun toplumsal iletişimdeki yeri. Kurgu Dergisi. 2000;17:27-34.

16. Rıza ET. Ĕ̆itim Teknolojisi Uygulamaları. İzmir: Anadolu Matbaa; 1997.

17. Baykul MC, Üret T. VM, UNIXX ve Windows Uygulamalaryla Internet. İstanbul: Beta Yayıncılık; 1996.

18. İnanlı M. Televizyondaki Çocuk Programlarının Beş-Altı Yaş Çocukları İçin Sözel Şiddet Ve Antisosyal Sözcükler İçerme Durumunun İncelenmesi. [Yüksek Lisans tezi]. Ankara, Türkiye: Gazi Üniversitesi; 2009.

19. Ayrancı Ü, Köşgeroğlu N, Günay Y. Televizyonda çocukların en çok seyrettikleri saatlerde gösterilen filmlerdeki şiddet düzeyleri. Anadolu Psikiyatri Dergisi. 2004;5:133-140.

20. Brown A. Media use by children under than 2 years. Pediatricks. 2011;13(1):129149.

21. Günaydın B. Çocuklara Yönelik Programlarda Toplumsal Cinsiyet Rollerinin Sunumu: TRT Çocuk ve Yumurcak Tv. [Uzmanlık tezi]. Ankara, Türkiye: Radyo ve Televizyon Üst Kurulu; 2011.

22. Ertürk YD, Akkor A. Çocuğunuzu Televizyona Teslim Etmeyin. Ankara: Nobel yayınları; 2006.

23. Villani S. Impact of media on children and adolescents: a 10-year review of the research. J Am Acad Child Adolesc Psyhiatry. 2001;40(4):392-401. 
24. Ülken F. Televizyon izlemede anne-baba aracılığı ile çocukların saldırgan davranışları arasındaki ilişki. Anadolu Üniversitesi Sosyal Bilimler Dergisi. 2011;11(1):195-216.

25. Altınkılıç Z, Özkan H. Televizyon izlemenin 1-6 yaş çocuk sağlığı üzerindeki etkilerine yönelik annelerin tutum ve davranışlarının belirlenmesi. İzmir Dr. Behçet Uz Çocuk Hast. Dergisi. 2014;4(3):186-194. doi:10.5222/buchd.2014.186

26. Kara T. Görsel Medyanın Aile Bireyleri Üzerindeki Etkileri Üzerine Bir Araştırma. [TUİK Uzmanlık Tezi]. Manisa, Türkiye: Türkiye İstatistik Kurumu; 2011.

27. Sungur S. Televizyon Yayınlarmın Çocuklar Üzerindeki Olumsuz Etkileri. Konya: Eğitim Kitapevi; 2008.

28. Gümüş A. Şiddetin Nedenleri. Toplumsal Bir Sorun Olarak Şiddet Sempozyumu. Ankara: Eğitim Sen Yayınları; 2006.

29. Çelik M, Kalenderoğlu A, Almış H, Turgut M. Tv programı sonrası gelişen ölüm kastı olmayan taklit intiharlar: 5 yaşında iki olgu. Arch Neuropsychiatr. 2016;53:83-84.

30. Öktem F, Sayıl M, Çelenk Özen S. Çocukların ve Gençlerin Televizyonun Zararlı İçeriklerinden Korunması. “Akıllı İşaretler Sınıflandırma Sistemi”. https://kms. kaysis.gov.tr/Home/Goster/74989?AspxAutoDetectCookieSupport=1. 2006. Erişim Tarihi: 19.12.2019.

31. İrkin A. Çocukların Gelişim Süreci Ve Televizyonun Etkileri. [Uzmanlık Tezi]. Ankara, Türkiye: Radyo ve Televizyon Üst Kurulu; 2012.

32. Kolucki B, Lemish D. Çocuklarla iletişim. Unicef. 2011. www.unicef.org/cwc. Erişim Tarihi: 25.12.2019.

33. Erdoğan S. Erken çocukluk döneminde televizyonun sosyal gelişime ve değerler eğitimine etkisi. In: International Conference on New trends in Education and Their Implications; 11-13 Kasım 2010; Antalya, Türkiye.

34. Aktaş C. İlköğretim okullarında medya okuryazarlığı eğitimi. In: 4. Uluslararası Çocuk ve İletişim Kongresi; 22-24 Ekim 2007; İstanbul. 
35. Arslan Ş. Televizyon Reklamlarının Okul Öncesi Dönem Çocuklarının Tüketici Davranışlarına Etkisi. [Yüksek lisans tezi]. Ankara, Türkiye: Gazi Üniversitesi; 2010.

36. Temizyürek F, Acar Ü. Çizgi filmlerdeki subliminal mesajların çocuklar üzerindeki etkisi. Cumhuriyet International Journal of Education. 2014;3(3):2529.

37. Doğan A, Göker G. Tematik televizyon ve çocuk: ilköğretim öğrencilerinin televizyon izleme alışkanlıkları. Millî Eğitim Dergisi. 2012;194:5-30.

38. Cesur S, Paker O. Televizyon ve çocuk: Çocukların TV programlarına ilişkin tercihleri. Elektronik Sosyal Bilimler Dergisi, 2007;6(19):106-125.

39. İnan T. Çizgi filmlerin okulöncesi çocuklarının problem davranışlarına etkisi. Journal of International Social Research. 2016;9(43):1432-1445.

40. Aksaçlığlu AG, Yılmaz B. Öğrencilerin televizyon izlemeleri ve bilgisayar kullanmalarının okuma alışkanlıkları üzerine etkisi. Türk Kütüphaneciliği. 2007;21(1):3-28.

41. Özakar S, Koçak C. Kitle iletişim araçlarınından televizyonunun 3-6 yaş grubundaki çocukların davranışları üzerine etkisi. Yeni Sempozyum Dergisi. 2012;50(1):31-39.

42. Temel M, Akgün Kostak M, Çelikkalp Ü. Çocuk kanallarında yayınlanan çizgi filmlerdeki şiddetin belirlenmesi. Deuhyo Ed. 2014;7(3):199-205.

43. Aral N, Ceylan R, Bıçakçı Yıldız M. Çocukların televizyon seyretme alışkanlıklarının yaş ve cinsiyete göre incelenmesi. Kastamonu Ĕ̆itim Dergisi. 2011;19(2):489-498.

44. Blumberg FC, Bierwirth KP, Schwartz AJ. Does cartoon violence beget aggressive behavior in real life? An opposing view. Early Childhood Education Journal. 2008;36:101-104.

45. Karaçor S. Reklam İletişimi-İnternet ve Gazete Reklamlarının Etkilerine Yönelik Bir Araştırma. Konya: Çizgi Kitabevi; 2007. 
46. Karaca Y, Pekyaman A, Güney H. Ebeveynlerin televizyon reklam içeriklerinin çocuklar üzerindeki etkilerini etik açıdan algılamalarına yönelik bir araştırma. Sosyal Bilimler Dergisi. 2007;2:234-242.

47. Asena MB. Gıda Reklamlarının Okul Öncesi Çocuklar Üzerindeki Etkilerinin Anneler Tarafından Değerlendirilmesi. [Yüksek Lisans Tezi]. İstanbul, Türkiye: Bahçeşehir Üniversitesi; 2009.

48. Ateşoğlu İ, Türkkahraman M. Çocukların tüketici olarak sosyalleşmesi. Süleyman Demirel Üniversitesi İktisadi ve İdari Bilimler Fakültesi Dergisi. 2009;14(3):215-228.

49. Folta SC, Goldberg JP, Economos C, Bell R, Meltzer R. Food advertising targeted at school-age children: A content analysis. Journal Of Nutrition Education and Behavior. 2006;38:244-248.

50. Kurt E, Altun T. Televizyon reklamlarının ilkokul öğrencilerinin beslenme alışkanlıklarına etkisi üzerine bir inceleme. Akademik Sosyal Araştırmalar Dergisi. 2014;2(7):393-408.

51. Dixon HG, Scully ML, Wakefield MA, White VM, Crowford DA. The effects of television advertisements for junk food versus nutritious food on children's food attitudes and preferences. Social Science and Medicine. 2007;65:1311-1323.

52. Ertürk D. Çocukluk Çağı Gelişim Dönemlerine Göre Medya Kullanımı, Çocuk Hakları ve Medya. İstanbul: Çocuk Vakfı Yayınları; 2011.

53. Tahiroglu AY, Çelik GG, Uzel M, Özcan N, Avcı A. Internet use among Turkish adolescents. Cyberpsychol Behav, 2008;11(5):537-543. doi: 10.1089/cpb. 2007.0165.

54. Uğurlu Ö. Elektronik dünyanın çocuk dünyasına yansıması: Temassız oyun kavramı bağlamında eleştirel bir inceleme. İletişim ve Diplomasi, 2014;2:51-6.

55. Şimşek İF, İşliyen M. Çocukların medya algısının resimler üzerinden analizi. Global Media Journal TR Edition. 2015;5(10):271-287. 